This item was submitted to Loughborough's Research Repository by the author.

Items in Figshare are protected by copyright, with all rights reserved, unless otherwise indicated.

\title{
Understanding multi-methodology: evaluating the perceived impact of mixing methods for group budgetary decisions
}

PLEASE CITE THE PUBLISHED VERSION

http://dx.doi.org/10.1016/j.omega.2010.06.008

PUBLISHER

(C) Elsevier

VERSION

AM (Accepted Manuscript)

LICENCE

CC BY-NC-ND 4.0

\section{REPOSITORY RECORD}

Franco, L. Alberto, and Ewan Lord. 2019. "Understanding Multi-methodology: Evaluating the Perceived Impact of Mixing Methods for Group Budgetary Decisions”. figshare. https://hdl.handle.net/2134/14639. 
This item was submitted to Loughborough's Institutional Repository (https://dspace.lboro.ac.uk/) by the author and is made available under the following Creative Commons Licence conditions.

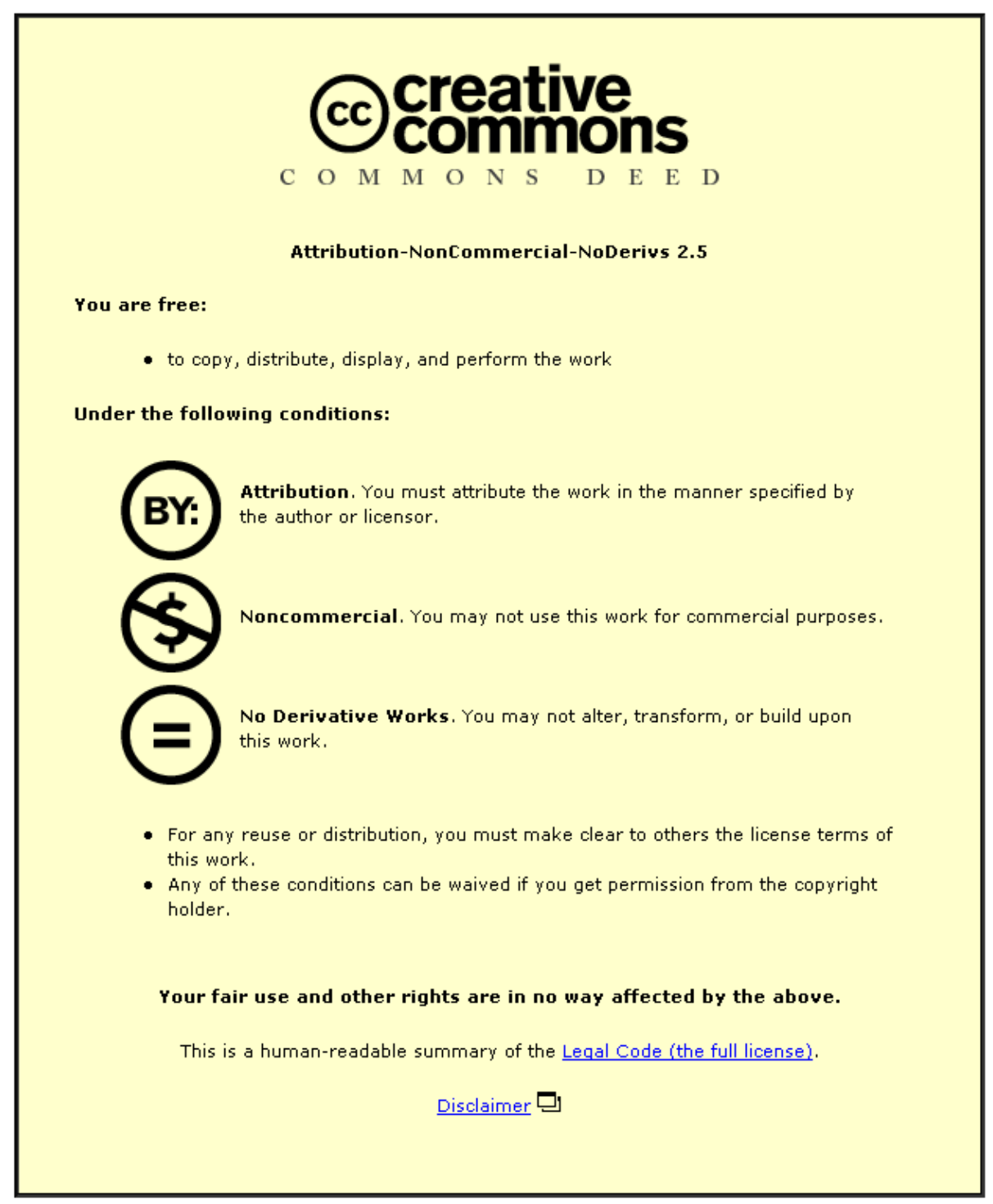

For the full text of this licence, please go to: http://creativecommons.org/licenses/by-nc-nd/2.5/ 


\title{
Understanding Multi-Methodology: evaluating the perceived impact of mixing methods for group budgetary decisions
}

\author{
L. Alberto Franco ${ }^{1}$, Ewan Lord \\ Warwick Business School, University of Warwick, Coventry CV4 7AL, UK
}

\begin{abstract}
This paper reports on the design and implementation of a multi-methodology intervention intended to support a budget prioritisation decision by a multi-organizational group tasked with tackling the problem of teenage pregnancy in an English borough. The intervention approach involved the combined use of cognitive/causal mapping and a multi-criteria decision analysis method to develop and prioritise a number of projects aimed at alleviating issues associated with teenage pregnancy. The paper describes and discusses the process of developing and applying the intervention approach, and provides an evaluation of its perceived impact by the client group. Drawing on the rich seam of data gathered over the course of our work with the multi-organisational group, we explore the varying degrees of impact that the mapping and multi-criteria evaluation methods achieved during and after the intervention. Analysis of the intervention data suggests that both methods were perceived to facilitate a different way of thinking and learning. In addition, we find that the mapping and multi-criteria evaluation methods successfully addressed participants' democratic and rational concerns. However, despite these reported positive effects, the full recommendations of the intervention were not implemented. An attempt is made to explain this outcome in terms of both, the multi-organisational context within which the intervention took place, and the nature of the group task. Directions for further research are then proposed.
\end{abstract}

Keywords: group decisions, multi-methodology, cognitive/causal mapping, multi-criteria decision analysis, evaluation, intervention.

\section{Introduction}

One of the most important developments to have emerged in the management science literature in recent years is 'multi-methodology' [1-5], a terms used to described the combined use of two or more methodologies (or part thereof) within a single intervention. Mingers and Brocklesby [1] argue that the highly complex and multidimensional nature of real-world problems makes multi-methodology interventions a necessary development. In addition, the characteristic 'phased-ness' of an intervention (e.g. appreciation, analysis, evaluation, action) implies that single methodologies may be more useful in relation to some phases than others, hence making the prospect of multi-methodology an obvious choice for researchers and practitioners. By adopting a multi-methodology approach, Mingers and Brockleby argue, interventions would be able to deal more effectively with the full richness of the real world.

Our general aim is to make a further contribution to the increasing literature on multimethodology applications (for a recent survey see [6]) by reporting on the design and implementation of an intervention, carried out by the authors, to help a multiorganisational group explore their budget allocation priorities. The intervention was designed and implemented to provide facilitated, model-driven decision support for the analysis and prioritisation of projects intended to alleviate issues associated with

1 Corresponding author: Tel.: +44 2476 524691; fax: +44 247654539.

Email address: alberto.franco@wbs.ac.uk 
teenage pregnancy in an English borough. The paper has an evaluative orientation and thus intends to increase our understanding of the impact of multi-methodology. We hope that the insights generated from the analysis presented here could help inform future multi-methodology research and practice.

In this paper we are concerned with the impact of the type of multi-methodology that involves the combination of more than one method or technique within a single intervention. Within the multi-methodology literature, a 'method' has been defined by Mingers [7] as a set of "well-defined sequences of operations that, if carried out proficiently, yield predictable results" (p.307). The specific methods studied in the research reported here are cognitive/causal mapping [8-10] and multi-criteria decision analysis [11]. Whist the joint deployment of these methods is not new [e.g. 12, 13, 14], most reported accounts of this type of multi-methodology intervention provide impact assessments mostly from the point of view of the 'interventor' (e.g. typically a researcher or a consultant; see, for example, [15]). In contrast, this paper seeks to unravel the views of those 'intervened' (i.e. the client group), and presents a systematic analysis of the research data generated during the intervention.

The rest of the paper is structured as follows. The next section describes the context of the intervention. Next, the rationale underlying the intervention design is explained, followed by an account of its deployment with the client group. Analyses of the intervention data are presented in the subsequent section. Issues concerning the role and impact of using different methodologies in a multi-methodology format to support group budgetary decisions are then articulated. The paper concludes with directions for further research.

\section{The intervention context}

The severity of the problem of teenage pregnancy in the UK was highlighted in a report by the Social Exclusion Unit [16] which set demanding improvements to be achieved by 2010. Up to 2005, the teenage pregnancy rate in the UK (42.3 conceptions per 1000 girls $^{2}$ ) had remained similar to that in the 1970s, while in most of Western Europe it had halved. This problem exhibits all the typical characteristics of a complex societal issue: multiple underlying causes, diverse and conflicting opinions on how to tackle it, and significant implications to society. Recognising this complexity, the SEU report advocated a policy of 'joined up working' to break long term, reinforcing cycles of social exclusion such as those resulting from teenage pregnancy. In 2002, all local authorities in England were required to set up a Teenage Pregnancy Strategy Group (TPSG).

Our client was one such group working for an English borough that encompasses a large area in East London. The area has significant issues of social deprivation and poverty, transience, mixed faiths and multi-ethnicity. In addition, it has a disproportionately young and needy population and a much higher rate of pregnancy amongst teenagers than in other boroughs of the city. Indeed, the borough has one of the highest teenage pregnancy rates in the country. In 2003, the number of conceptions for teenagers within the 15 to 17 year-old range was about 55 per

${ }^{2}$ Source: http://findoutmore.dfes.gov.uk/2005/08/teenage_pregnan.html 
thousand, and the borough was under high pressure to bring this number down to below 30 per thousand by 2010 .

The team tasked with making the strategic decisions to achieve this target, hereafter referred to as the Teenage Pregnancy Strategy Committee (TPSC), was made up of representatives from the borough's council, the National Health Service, the education authorities, and others stakeholders such as the voluntary sector which included young parent representatives. Its budget was made up of a complex mix of direct funding, contributions from the participant organizations, and government incentives for achieving certain targets and key performance indicators.

At the time of our engagement with the TPSC in 2006, several projects had been running for some time and there was a perception that some degree of success had been achieved. However, although the ongoing projects had reduced the teenage pregnancy rate, it had not done so at a pace sufficient to achieve the TPSC targets by 2010. As a result, there was recognition within the TPSC of the need to explore more effective and efficient ways to achieve their targets. An initial meeting between the authors and the TPSC coordinator (our eventual sponsor) was held to explore the possibility of conducting an action research project to help the TPSC with this need. After some discussions it was mutually agreed that focusing on the budget prioritisation process would be potentially beneficial to the TPSC. The methodology adopted is described next.

\section{Designing the intervention}

The intervention was conceived within an action research paradigm [17]. Following Checkland and Holwell [18], we started the process of designing the intervention by articulating the problem situation faced by the client group. At the broadest level, the problem domain was that of alleviating teenage pregnancy levels and associated issues with it. Specifically, the problem task faced by the client group was one of allocating limited resources to projects intended to alleviate issues associated with teenage pregnancy within the borough, using a value-driven framework. Our intervention thus had to be designed in such a way that it could capture the TPSC's expertise and knowledge about teenage pregnancy issues within the borough, together with their views of the potential value contribution of each of the proposed projects, and effectively use these available sources of expertise, knowledge and perspectives in deciding the best possible allocation of available resources to projects.

Next, we drew on a 'framework of ideas' about the problem situation and about intervention methodology. Elements of our 'framework of ideas' included, for example, the notion of 'divergent' and 'convergent' thinking as key elements of a facilitated group decision process [19]. When group members engage in divergent thinking they share their knowledge of the situation of interest, surface their initial interpretations of the issues of concern, and of the options available to them; when convergent thinking is dominant, group members identify commonalities in views, form a consolidated perspective of the issues or options, and work out a resolution that take various positions into account. It as been argued that both divergent and convergent thinking are needed for effective group decision making. A never-ending increase in ideas or options is likely to lead to information overload; similarly, consensus that is formed without a thorough exploration of issues can lead to inferior 
decisions [20]. Our intervention had therefore to be designed to effectively support these two complementary thinking processes.

Another key element of our framework of ideas was the notion of multi-methodology as an effective means to tackle the complexity of real-world situations. The complexity in this case came from two sources. First, the domain of teenage pregnancy exhibited multiple and interconnected issues associated with poverty, education, religious faith, ethnicity and ethics, and was viewed and valued differently by the TPSC members and other stakeholders in the domain; second, the task of allocating resources to projects was in itself complex, as it required qualitative and quantitative considerations of a relatively large number of projects, together with the negotiation among stakeholders of appropriate criteria which were to be used to evaluate them. For these reasons, the intervention design needed to consider qualitative as well as quantitative methods in order to tackle domain and task complexity.

Several approaches to multi-methodology design and choice of methods can be found in the literature, ranging from those that are essentially theory-led [e.g. 21, 22, 23] to those that are practice-led [e.g. 4, 24, 25-27]. Despite this apparent plethora of design frameworks, we argue, like others [e.g. 27, 28], that intervention design is not an exact science and therefore it is unlikely that a prescribed 'best way' of combining methods exists. Nevertheless, for the purposes of guiding the impact assessments of the different elements of our multi-methodology intervention, it is helpful to be explicit about the design framework eventually chosen. For this we draw upon the work of Mingers [29, 30], who suggests that an intervention design can be articulated along two dimensions: the multiple-aspects of the problem domain, and the multiphases of intervention activity. Specifically, a fully comprehensive intervention design would need to cover all three constitutive aspects of a domain -i.e. personal, social and material-, and all four general activities of an intervention -i.e. appreciation, analysis, assessment and action.

In applying the above design framework to our intervention, it can be stated that the cognitive/causal mapping method has strengths in the area of personal and social dimensions, but it has little to offer in the material dimension. Cognitive/causal mapping is a diagrammatic technique for depicting the way individuals or groups think about a particular issue of concern [8-10]. Derived from Kelly's psychological theory of persona constructs, cognitive/causal mapping is aimed at eliciting personal beliefs about the issue, rather than material aspects associated with it. Furthermore, it is also informed by organisational negotiated order theory, and thus can offer support for the social dimension. On the other hand, multi-criteria decision analysis methods are typically used during the assessment and action phases of an intervention, covering the evaluation of alternative options, and identifying the best possible one [11]. The methods are grounded in decision theory, and their purpose is to produce models that capture the judgements of an individual or group about the relative attractiveness of potential options. The models are not meant to be a physical representation of these options, though the options are potentially-realizable in the material world. In addition, when deployed as a 'facilitated modelling' approach [31], multi-criteria decision analysis takes into account (but does not explicitly model) different stakeholders and viewpoints to produce a representation that conveys a 'shared social reality' [32]. Thus we argue that multi-criteria decision analysis can be 
placed broadly across the personal/material dimensions. From a multi-methodology perspective, then, an intervention design based on the combined use of cognitive/causal mapping and multi-criteria decision analysis complements the strengths and weaknesses of each method considered individually.

We stated earlier in the paper that our focus was on mixing methods, rather than whole methodologies, within a single intervention. Issues of mixing methodologies or methods are well documented in the literature [e.g. 1, 4, 27, 33-35]. In general, they are centred on the feasibility of combining either methodologies or methods that come from different philosophical paradigms. Our preceding characterisation of both methods should have made clear that these issues were not particularly salient in our case. Although based on different theoretical grounds, our chosen methods share an interpretive orientation to intervention and, as such, it is reasonable to consider them as cognate approaches that can be placed within the same paradigm associated with soft OR methods [36-38].

It is also worth noting that the choice of methods for intervention can depend heavily on the nature of the task. In our case, the task required a convergent process of evaluation and choice for which a particular multi-criteria decision analysis method was deemed appropriate. The task also required a thorough examination of issues before the structure of objectives and associated criteria were agreed. Such divergent processes can be enhanced when supported by problem structuring methods such as cognitive/causal mapping. Applying both methods in a single intervention, however, requires a different set of modelling skills on the part of the analyst, particularly with regards to how data is collated, coded and manipulated (see [31] for a useful discussion of these issues). Given the authors' personal backgrounds and experiences with the methods, these requirements did not pose a significant issue. Specifically, the first author has an engineering background and experience in decision analysis prior to start working in the field of problem structuring methods, whilst the second author has a background in psychology and training in facilitated problem structuring and decision analysis. Background, knowledge and experience can help to bring about personal competency for mixing methods in practice [27, 35, 39] and, therefore, our particular choice of methods seemed both natural and useful for the task at hand.

In the final design, the intervention comprised two phases to be deployed in a 'serial' fashion [40].. In phase one, cognitive/causal mapping [8-10] would be used to elicit, share and examine stakeholders' views of the situation, so that an improved and shared understanding of the issues related to teenage pregnancy could be achieved among stakeholders. This phase would start with cognitive mapping interviews and a facilitated, computer-supported interactive group workshop using the Group Explorer networked workstation system (www.phrontis.com) running along the Decision Explorer mapping software (www.banxia.com). In phase two, a multi-criteria decision analysis method would be used to model stakeholders' preferences and judgements (based on the improved and shared understanding achieved during phase one) in order to highlight a portfolio of projects which would produce the highest value in relation to the aims of the TPSC. Specifically the work during phase two would involve a multi-criteria portfolio analysis via a facilitated, visually interactive group workshop. The modelling approach follows the multi-criteria portfolio analysis of area-grouped projects described in Phillips and Bana e Costa [41], and uses the Equity software (www.catalyze.co.uk) as the modelling tool. In a nutshell, the 
approach clusters candidate projects for funding within budget areas, and prioritises them in order to produce a portfolio that provides the best overall value for a given budget. The embedded principle for prioritising projects is that projects should be ranked using the marginal benefit per unit of cost (see compelling arguments in its favour in [41]), where benefits are usually multi-dimensional.

\section{Deploying the intervention approach}

\subsection{Cognitive mapping interviews}

The purpose of the cognitive mapping interviews was to elicit and structure the stakeholders' knowledge of the problem situation, and to stimulate new causal thinking, in preparation for the multi-criteria evaluation to be undertaken in the second phase of the intervention. Eight representatives from the TPSC were interviewed by the second author for approximately 45 minutes each. These included: one of the two TPSC co-chairs; the TPSC coordinator; the family planning lead and chair of the prevention sub-group; the representative of the communications subgroup; the representative of learning and schools; representative of children's rights and sex education; the representative of the young parents forum; and the support to parents personal advisor.

The interviewer mapped the interview following the general guidelines listed in Bryson et al [10], e.g. mapping on A3 paper during the sessions, interviews and interviewee sitting at 90 degrees (or less), etc. Interviewees were reassured of the confidentiality of their maps but that the unnamed maps would be available to other participants in the intervention. The initial framing question in the interviews was future focussed but otherwise as open as possible. The prompt used with an interviewee was "what do you think will be the issues in and around teenage pregnancy in this borough until 2010?”

The shape of the resulting cognitive maps elicited immediately revealed some differences among interviewees (e.g. wider, flatter maps versus narrow, taller maps). As an illustration, Figure 1 below shows an excerpt from a cognitive mapping interview. Nodes in the map contain statements describing different aspects of an issue or issues, and links between nodes denote means-end chains of arguments - for an extensive treatment of cognitive mapping see Bryson et al [10].

\section{PLACE FIGURE 1 ABOUT HERE}

An overall map was produced by merging the individual maps using Decision Explorer. The software allowed us to accommodate similar views by merging map nodes without altering the underlying map structure. Differences in views were preserved (but kept anonymous) so that they could be aired during the group causal mapping workshop (see next section). Following Eden's guidelines [9], analysis of the individual maps enabled us to gain a good level of understanding of the different multi-organisational tensions present within the TPSC. These were mainly derived from strongly-held views within the TPCS about how to tackle teenage pregnancy issues. 


\subsection{Group causal mapping workshop}

Six participants, four of whom had been previously interviewed, took part in a oneday, 6-hour group casual mapping workshop held at Warwick Business School in the summer of 2006. The other two were: the second TPSC co-chair, and a member of the borough's strategy board. Although the latter was not a member of the TPSC, he was the faith groups' representative who had influence over TPSC and the borough's funding stream (therefore a key stakeholder). The general purpose of the workshop was to build upon the findings of the cognitive mapping interviews, create a shared and improved understanding of the issues among the workshop participants, and to structure a set of fundamental objectives and associated attributes or evaluation criteria [42] in preparation for the subsequent multi-criteria evaluation phase. Content and process facilitation tasks were split between the first and second author respectively.

The causal map produced at the workshop was analysed using the notions of 'domain', 'centrality' and 'clustering' [9], which allowed the identification of a set of interlinked key issues faced by the TPSC group. These included issues related to increasing self-esteem of young women, engaging with faith groups, continuing funding for community health services, improving intelligence gathering, providing better educational opportunities for young parents, and ensuring that the voice of young parents was integrated into TPSC's strategy and delivery.

The causal mapping approach was so stimulating for the group that little time was left to adequately surface evaluation criteria. In an attempt to structure the criteria needed for phase two while the group were still together, the focus of the latter part of the workshop was thus moved to structuring a 'value tree'. While the mapping methodology seemed intuitive to the participants, the technical requirements associated with developing a value tree and associated evaluation criteria [43] were received less enthusiastically by participants. Evaluation criteria had thus to be further developed off-line with the TPSC coordinator prior to the next stage of the intervention.

\subsection{Multi-criteria portfolio analysis workshop}

The aim of the second (convergent) phase of the intervention was to identify portfolios of projects which would provide the most overall value to the TPSC across a range of annual budgets. Although the exact amount of the budget was uncertain at the time of the intervention, the TPSC had realistic expectations about its limits.

A multi-criteria portfolio model was built using the Equity software prior to the workshop. One of the characteristics of Equity is that it requires projects to be grouped into budget areas. However, one potential caveat is that this requirement can place a heavy cognitive demand on the users if there are a large number of budget areas and/or projects to be considered. Furthermore, research on biases associated with weighting multi-criteria decision analysis models [44, 45] suggests that a certain "balance" may be needed in terms of the number of projects within each budget area, otherwise an area with a large number of projects may receive a disproportionately heavy weight. Therefore, both budget areas and projects were kept to a manageable level during the analysis. 
TPSC's areas and associated projects being funded at the time of the intervention provided the basis to start building the project portfolio model. The initial model contained 41 projects (including a "Do Nothing" option for each area) organised into nine areas of cumulative or mutually exclusive options which could be usefully compared with each other. The nine areas initially modelled (see Figure 2) were: 'Clinical Services', 'Media', 'Events', 'Young Parents Involvement', 'Sex and Relationship Education', Support to Parents', 'Youth Projects', 'Workforce Development', and 'TPSC Staffing'. They were subsequently refined into seven areas.

\section{PLACE FIGURE 2 ABOUT HERE}

Evaluation criteria were articulated in terms of those aspects which could help discriminate the projects. Initial criteria were derived from articulating the importance of the key issues identified during the analysis of the overall causal map, by 'laddering up' on these issues [8]. This initial criteria set mainly represented aspirational objectives of TPSC, and thus needed to be translated into measurable attributes. Despite recent development in the quantification of causal maps [e.g. 46], the procedure followed was 'ad-hoc' but relied on the judgement and experience of the facilitators, a common practice for articulating evaluation criteria from a causal map $[13,14]$.

Apart from the cost criterion, seven benefit criteria were agreed for the model and validated at the beginning of the multi-criteria evaluation workshop: two criteria related to core objectives (minimise number of conceptions among teenagers aged 15 to 17; and, maximise number of young parents back into education,); one criterion representing the TPSC's range of extra benefits (other than those included in the previous two); a financial cost criterion; two temporal criteria (speed of impact and sustainability of impact), and one related to uncertainty (i.e. confidence in achieving the intended benefits).

We helped participants to score the project against the benefit criteria. The scoring of areas which seem unproblematic was carried out first, so that the participants had time to get used to the scoring method. Overall, participants had little problems with directly rating the projects against each criterion. However, the group discussions about the scores and the required cross checks of the results took a considerable amount of time. Initial results from running the model led to its restructuring, during the workshop, by the participants themselves. For example, the options within the 'TPSC Events' area were redefined to represent a more realistic set of (mutually exclusive) alternatives (two small events; one small event and one big event; three small events; one mega-event). In addition, some areas were reduced and combined with others. For example, the Youth Projects area was removed from the model and its minimum level (i.e. one Youth Project) included as part of the 'Sex and Relationships' (SRE) area. This change was motivated to assess whether any youth centres at all, none of which had been funded with the previous year's budget, should be included in the portfolio.

Once all projects had been scored against each criterion, much of the rest of the later part of the workshop was spent weighting the model. Participants seemed to grasp the notion swing weighting without major problems, which allowed the elicitation of 
within-criterion weights and across-criteria weights (for further details of these concepts see [41]).

A final model was completed with the workshop participants, which showed the impact of a range of budgets on the TPSC portfolio. As the TPSC was facing budget cuts for the following year, the group was asked to propose a portfolio which they could feasibly fund next year. Point ' $\mathrm{P}$ ' in Figure 3 represents this proposed portfolio, with its associated aggregated costs and aggregated benefits. Point ' $\mathrm{B}$ ' corresponds to an alternative portfolio which could achieve a higher aggregated benefit for (roughly) the same level of aggregated cost. Finally point ' $C$ ' stands for a cheaper portfolio capable to achieve (roughly) the same aggregated benefit.

\section{PLACE FIGURE 3 ABOUT HERE}

We then helped the group to examine Equity's feedback results on the highest value (benefit:cost) portfolio at various budgets. Participants were immediately surprised to see some of their flagship projects replaced by more, smaller projects. In particular, projects within the 'Clinical Services' area appeared to be very expensive and not being picked up as efficient by the portfolio model. These results were counterintuitive to many of the participants, as some of these projects were considered to be at the core of the TPSC strategy. The political consequences of actually adopting the more efficient portfolios were then raised, and Equity was used to explore possible adjustments which would make certain portfolios more politically feasible. The portfolio model was in effect being used as a 'transitional object' $[47,48]$ by the participants. A sensitivity analysis of across-criteria weights was conducted and the model was subsequently refined in a 'back room' analysis. The results of this subsequent work were then fed back to the TPSC at an away day.

At this point our engagement with the TPSC ended. In a subsequent budget planning meeting of the TPSC, it was agreed that some of the projects within the clinical services area were still going to be funded albeit from a mix of sources within and outside the TPSC. It was noted, however, that the actual impact of these projects would be monitored and the decision to fund them revisited the following annual budget cycle in the light of the recommendations implied by the portfolio model.

\section{Evaluating the intervention}

The previous sections have described the intervention rationale and its subsequent implementation within the TPSC context. This section presents the analysis of the research data generated during the intervention, which comprised a mixture of sources including records from the two modelling workshops, field observations and notes, responses to a post workshop evaluation questionnaire, and transcripts of taperecorded, semi-structured interviews carried out with TPSC members. Regarding the latter, all TPSC members who participated in the two modelling workshops were interviewed 2-3 months after the intervention took place. The general purpose of these interviews was to capture their perceptions of the usefulness of the different aspects of the intervention. The average interview lasted between 45 and 60 minutes. All this information provided a rich set of qualitative evaluation data with which to examine the impact of our multi-methodology intervention with the TPSC. 
The data was coded and analysed using an approach based on grounded theory [49]. The potential perceived for generating an understanding of the subjective meanings participants attributed to their experience of using mapping and multi-criteria evaluation methods during the workshops was the main motivation for adopting this approach to data analysis. Furthermore, the analysis sought to understand how these subjective meanings fit into larger patterns of interaction within which the intervention was embedded. This approach to data analysis has been used by management scientists wishing to understand complex interventions, particularly by those working within the 'soft' operational research domain [e.g. 50, 51, 52].

A grounded theory approach offers a way of examining qualitative intervention data that systematically develops theoretical themes or hypotheses about the phenomena which have been observed. It allows the systematic identification of a set of conceptual categories and their interrelations which develop as the analysis continues. These emerging 'grounded' concepts, derived from the data, are then used as the basic building blocks of the growing theoretical understanding of the phenomenon under study [53]. The coding and categorizing process was facilitated by the use of the Decision Explorer software.

Two levels of analysis were carried out. First, the data was broken into meaningful discrete parts and coded following standard mapping guidelines [54]. Next, groups of coded data were clustered and assigned a 'cluster label' based on the imagery or meaning the coded data evoked when examined comparatively and in context. 'In vivo' labels (i.e. actual concepts used by interviewees) were used whenever possible. A second-order analysis was conducted in parallel with the first-order analysis. While the first- order analysis sought to stay with the data and let the data 'speak for itself' [49], the purpose of the second-order analysis was to develop a higher level of abstraction by conceptualising how the various clusters of material may be related, and aggregating the material into broader and interrelated analytical categories or 'themes' to provide a theoretical framework for organising the emergent findings.

\subsection{First order analysis.}

A first-order analysis of the data produced a number of themes. First, TPSC members expressed the unanimous view that the intervention helped them think in a different way about teenage pregnancy issues. In relation to the mapping workshop, participants stated that they were forced to think 'laterally' and analyse issues in more breadth and depth that would have been normally the case within TPSC strategy meetings. It also allowed them to re-examine the ongoing TPSC strategy. One of the major reasons for these views was the perceived ability of the computer-supported mapping technology, assisted by the facilitators, to gather and structure a large number of issues 'on-the-hoof', and produce common themes despite participants' diversity of backgrounds and organisational roles.

The multi-criteria evaluation workshop also appeared to have facilitated a different way of thinking for the TPSC. Participants stated that the multi-criteria scoring changed their thinking about how they commonly diddo things. By separating benefits from costs and thinking about service areas in discrete and quantitative terms, they were able to achieve focus and identify the contribution that the different elements of their programmes had to the overall impact of the work of the TPSC. The evidence 
shows that the TPSC did not often match up money spent with impact on a unit for unit basis, and participants claimed that the multi-criteria evaluation workshop allowed them to adopt a more structured way of thinking about the value provided by their activities, although some of them did express a concern about how realistic these value measurements were.

Second, the data suggests that learning was achieved within the TPSC as a result of the intervention. Participants asserted that through the mapping workshop they were able to appreciate and raised their awareness of the work done by other TPSC members. Furthermore, new perspectives on issues never explored before were possible. For example, during the mapping workshop a discussion started around emergency contraception, terminations and religion which, according to some interviewees, had never been aired before in TPSC meetings. Finally, some expressed that the insights gained about how others think and work enabled them to find novel ways of challenging the work of the TPSC or overcoming blocks with work colleagues. For example, there is evidence that the TPSC coordinator used the maps produced at the workshop in subsequent meetings with TPSC members in this way.

Learning was also attributed as an impact of the multi-criteria evaluation workshop. In particular due to the elicitation of evaluation criteria and the counterintuitive nature of the outputs produced by the portfolio model. As stated in the previous section, the results of the portfolio analysis suggested that some of the projects within the clinical services area were not as efficient in delivering value compared to other, less costly, projects within the portfolio. This was not what was expected and certainly closing down these projects would have not even been considered if a standard TPSC budgetary decision process had been followed. And although these less efficient projects were eventually funded (despite the model recommendations), the evidence shows that the learning from the multi-criteria evaluation experience had an immediate impact on subsequent TPSC meetings. Furthermore, there were signs of a change in participants' work attitudes towards the budgetary decision making process. For example, some TPSC members expressed that they were now focused on articulating more explicitly the links between the impact of some of their projects and the evaluation criteria developed during the intervention, as well as providing appropriate evidence of this impact.

In summary the first order analysis identified new ways of thinking and learning as the main impacts perceived by TPSC members. These impacts are consistent with the claims that facilitated modelling methods, such as those employed here, provide group members with a shared language and structured thinking framework that improves communication and increases insight about the situation or task of concern (for recent reviews of the impacts claimed for facilitated modelling methods see [31, 55]).

It is noteworthy that the declared perceived impacts are not different from the ones claimed when the methods are deployed in isolation. It can be argued however, that the enhanced communication and insight perceived in the multi-criteria evaluation workshop was positively affected by the impacts perceived and benefits from the mapping workshop. Unfortunately there was no evidence in the data pointing towards the linear and facilitative nature of the benefits derived from combining methods in this intervention. This is certainly an aspect worthy of further investigation. 
In order to further understand the contributory nature of the impacts identified above, a second-order analysis was conducted. This involved revisiting the data and reflecting on the findings, looking 'beneath the surface' to identify some 'middlerange' theories about the effectiveness of the intervention in the TPSC context. The theories that surfaced relate to the ways in which organisational actors judge the usefulness of modelling as a tool for effective decision making. Specifically, the data shows that the two modelling methodologies deployed within our multi-methodology intervention were deemed effective, but their effectiveness was associated with two competing concerns of decision making: democracy and rationality. These aspects are articulated next.

\title{
5.2. Second order analysis.
}

The evidence suggests that some TPSC members exhibited this concern and that they evaluated the usefulness of the intervention in terms of the extent to which it enabled them to make themselves noticed, make their views heard, and even persuade others. A participant commented that:

\begin{abstract}
"I think it allowed for some more free thinking, I don't think when you work for local authority you do it very often...it was helpful because it obviously meant I got my point across in terms of the work I do with young people and more involvement with young people, young people's perspectives on delivering programmes. Once it was up there [on the map] people obviously had to take note of it. That was good and actually what I found since then was when we had strategy meetings people would say it rather than it'd always be me saying 'what about young people, what do they think'. Usually it's me who has to say that kind of stuff and [the mapping] kind of raised their awareness a little bit more. I've worked on the board for 3 years so it's quite nice to know that if I'm not there somebody else will bring it up"
\end{abstract}

The mapping workshop thus allowed some members to raise and register their views 'up there', on the map. But raising them and registering them was only part of the impact observed. Linking their views to those of others made the former even more salient in the eyes of others:

“The mapping thing...it wasn't just in one section, its part of Children's Rights and Young People's Involvement and Young People's Services...it went into other areas on the map, even if I didn't necessarily put them there to be processed...that happened."

Concerns with democracy in decision making are associated with issues of openness, participation and consensus. On the other hand, concerns with rationality in decision making are associated with notions of efficiency, control, and accountability. The data shows that for some members it was important to be objective or 'scientific' about the things they do in their work, and to inject rigour to their decision making processes. In the word of two senior participants:

"I think we are just not used to doing it in such sort a way in the public sector...we don't use such tools, I don't think in our decision making, even in quite big budgets, I'm thinking of the really big commissioning budgets we have, a lot of them are quite fixed really, and its only now that we are starting to think about how we; you know I suppose when there are more options coming on the stream of that joining them up with such a care budget and education budget, we are now thinking about what some of the opportunities might be, single scientifically sound."

"I think it's just sort of trying to apply some science to it really, making us think in more detail about which bits of our programmes are having an affect. Up to now I think we think well its not always been clear, throwing a whole bunch of ideas at something but never really knowing which element of those 
are, you know you get some evaluative feed back from the individual programmes but it's really trying to pin down exactly what elements of those programmes or which programmes, because some of them are quite small, what affect are they having proportionately on the overall outcome? Which it's sort of a scientific approach I think."

This concern for rationality appears to have been addressed at least partially by the multi-criteria evaluation workshop, as illustrated in the following quotes:

"I think the [first] positive is [that the multi-criteria modelling] would allow us to go to our commissioners and say that we've applied some sort of rigour to the decision making process, and that it hasn't been just a few people sitting round a table having a discussion and then thinking 'well OK', you know what mean...outsiders can see that you've got some sort of rigour to the decision making process, I think that would be wise. I suppose the second one [is that] it did get people to think more about what the different effects of different areas to the programme was."

"We did say that if there were any flexibility, any flexible elements of the budget that we should look to using this model. I think it would be really good, it would be quite an innovative way to look at not only just the teenage pregnancy budget but some of the other things we do."

From a group decision making perspective, concerns for democracy and rationality can be at conflict with each other. Engaging in a participative multi-party dialogue can take up significant time and thus considered inefficient from a rational perspective. Conversely, the quantification of objectives and the drive for efficiency in decision making could be viewed as too detached from the need to negotiate consensus in a participative manner. In terms of impact, the evidence suggests that participants viewed the two methodologies used in the intervention were addressing only one of these concerns at a time, and thus represented a trade-off. This is illustrated in the following quotes, where participants compare the mapping workshop with multi-criteria evaluation workshop:

"I think that obviously spending time like that is quite constructive for the kind of group we've got anyway in building relationships, etc. I think it gives a framework to have discussion and certainty sets out to give equal weight in terms of opinion...[But] I think if someone had come out in the mapping exercise and questioned the inclusion of [name of service] having an impact here and there, the idea would have got rubbished...well not rubbished but it certainly wouldn't have been given the same validity of going through a process of scoring against criteria."

"I think the bit that added kind of most weight to it was the scoring at the end, I think that because that's where people felt they had a real impact into the model...Yes doing the weighting etc... and all the other scoring, I think everyone else found the other bits quite useful, the interviews, the maps, etc... but the kind of end [multi-criteria evaluation] model...I think was all about that scoring for people."

At a general level then, the different methodologies deployed within our multimethodology intervention appeared to have satisfied two distinct and competing concerns. These results are somehow not surprising, as one would expect that a multimethodology intervention will be perceived as addressing multi-dimensional concerns. Furthermore, it can be stated that participants' views were consistent with the underlying orientations of the methodologies: a key feature of mapping, like that of most problem structuring methods, is that it facilitates group dialogue through increased openness and participation [56-58]; multi-criteria methods, on the other hand, have an explicit focus on objective setting and evaluation as a means to produce efficient decisions $[11,59]$. 


\section{Discussion}

The impact of modelling in management science interventions has often been associated with the quality of the analyses and recommendations it produces. From the preceding discussion, however, it should be clearer that organisational actors also use other competing criteria and this is particularly true of multi-methodology interventions.

Was our intervention successful? As already stated the final recommendations from the intervention were not fully implemented. Can the competing concerns identified above explain this lack of full implementation? We examine this issue next, by developing a hypothesis which requires further verification.

The multi-organisational context within which the intervention took place offers one possible explanation for the lack of implementation in this case. The TPSC was a multi-organisational group with a relatively 'flat' hierarchy, diffuse power, and weak authority relationships. Within this context we would thus expect multi-organisational actors to engage in wider participation about issues and considerable negotiations in order to reach decisions that are considered politically feasible and legitimate. For many important issues associated with teenage pregnancy, several TPSC members held strong but contradictory views about what should be done. The mapping workshop facilitated TPSC members' attempts to make these views heard by others through their systematic articulation and debate during group discussion. However, no decisions were reached at the end of the mapping workshop as this was designed as an input to second phase of the intervention. The mapping workshop was, therefore, perceived as unproblematic.

However, the multi-organisational nature of the TPSC implied in this case that neither the norms of democracy or rationality were dominant, the latter being typically associated with the multi-criteria portfolio analysis workshop. As a result, the actions implied by the quantified results produced by the portfolio model were highly contested. This may explain the difficulties experienced by the TPSC in taking on board our recommendations of closing down the projects within the clinical services area. With respect to the quantification element of our intervention then, we hypothesise that the multi-organisational nature of the TPSC may have affected our ability to reconcile the diversity of values and interests present in the TPSC.

An exacerbating factor is the nature of the group task itself. Making budgetary decisions, although a routine planning task in organisations, is a complex endeavour due to the usually high number of managerial activities seeking funding, variability in budgets, the existence of multiple and (usually) conflicting objectives, and the need to consider a budget allocation that is collectively efficient. Our use of multi-criteria evaluation methods was intended precisely to tackle these complexities. However, as the outcome of a budgetary decision will inevitably mean that there will be winners and losers in the organisation, managers will engage in political negotiation to fight either to retain or increase their individual budget quotas. Indeed at the time of our intervention, decisions about the TPSC budget had negative consequences for some of the members (e.g. closing down some of the projects within the clinical services area meant laying off people which in turn meant that the role of a key TPSC member may end up being questioned). This also may explain why all the model recommendations were hard to take on board. 
To summarise, the salience of political considerations associated with the budgetary process within the TPSC posed a serious challenge to our ability to have an impact in terms of implementing all of our recommendations. Furthermore, the case shows that, when the norms of rationality are not dominant, implementation of quantitative modelling recommendations is problematic.

The remaining question is: what could have we done differently? Certainly we could have spent more time researching the context and budget processes within the TPSC to further increase our awareness of the political implications of different recommendations during the intervention design phase. For example, the 'intervention', 'cultural' and 'political' analyses in soft system methodology (i.e. Analyses 1, 2, 3) [60], or the boundary in critical systems heuristics [61] could have both enriched our intervention design, and be used to improve our understanding of the socio-political dimensions of the problem domain.

What about the facilitated modelling process itself? Our approach to structure the areas and option produced a set of budget areas which were not much different from the budget areas already in place within TPSC. As a result it was relatively easy for TPSC members to identify candidate projects for funding within their own areas, and then score them against evaluation criteria. The disadvantage was, however, that the resulting portfolio model structure also made it easier for people to 'fight for their corner'. An alternative then is to structure the areas \& options using a bottom-up approach. In this way, political feasibility is increased by having 'new' budget areas that cut across multi-organisational roles and thus reduce the possibility of each actor fighting for their own funding.

Notwithstanding the above issues, it is important to note that the success of an intervention cannot be restricted to the issue of implementation alone. For example, Connell [38] argues that intervention success along two dimensions: purpose and evaluation focus. The first one focuses on whether the intervention is designed to gaining insight about the problem situation or to provoke organisational change; the second one is concerned with whether the intervention is about structuring issues or achieving an outcome. Clearly our intervention did not provoke major change, but was successful in gaining insight about the value of a range of projects aimed at alleviating teenage pregnancy issues. Furthermore, the outcome achieved in our intervention was a prioritised list of projects, and the modelling approach facilitated this outcome. So some success, albeit a modest one, can be claimed for our intervention.

\section{Conclusions and directions for future research}

In this paper, we have examined the impact of a multi-methodology intervention that comprised the combined use of problem structuring and multi-criteria evaluation methods to support group budgetary decisions. As advocated by Mingers [7], Jackson [36] and Pidd [4], the real-world problems that management science wishes to tackle need the adoption of a multi-methodology, pluralistic or complementary approach to analytic interventions. To our knowledge, there is a dearth of published studies that have systematically assessed the impact of management science interventions, particularly multi-methodology ones. Furthermore, published evaluations have 
focused mainly on a single method or methodology [e.g. 52, 62, 63]. The research reported here takes a step towards filling this gap, by providing an evaluation of the perceived impacts of two methods deployed within a single intervention.

Cognitive/causal mapping and multi-criteria decision analysis methods have typically been deployed in isolation, rather than combination, and with distinct intervention process foci (for notable exceptions see [12-14]). In general decision analysts assume that individuals and groups are 'bounded rationals' with limited information processing capabilities and prone to cognitive biases [e.g. 64], and thus the task of decision analysis is to reduce both cognitive complexity and any source of behavioural bias which may be present during the intervention. Problem structuring analysts, on the other hand, tend to be more concerned about helping groups to achieve effective participation, dialogue and negotiated consensus [e.g. 65, 66] during the intervention.

The experience reported here suggests that when combining cognitive/causal mapping and multiple-criteria decision analysis methods in a multi-methodology intervention format, their separate foci can create opposite tensions that play a critical role in how a client group evaluates the effectiveness of the overall intervention. In particular, we find that cognitive/causal mapping is perceived and appropriated as a tool that satisfies democratic concerns of a budgetary decision process between multiorganisational actors. By using it in this way, mapping facilitates learning and new ways of thinking among actors. Multi-criteria evaluation, on the other hand, is valued as a tool that conveys rationality, and that also facilitates learning and new ways of thinking. However, the advantages that result from attempting to use quantitative modelling to achieve a collectively efficient budget allocation in a multiorganisational setting increases the potential for conflict and politics, and thus poses a significant challenge to the implementation of an intervention's recommendations.

We hypothesise that the intervention impacts observed may be related to the organisational context within which the multi-methodology is undertaken, and the contested nature of budgetary decisions. Empirical research of decision making suggests that the role of formal analysis (and, in particular, quantitative analysis) in pluralist organisational forms (such as the TPSC) may be limited due to the existence of multiple actors with diverse values and interests, ambiguity of goals, diffuse power and complex lines of accountability [e.g. 67, 68,69]. Our experience seems to concur with this evidence. Indeed, despite a careful intervention design and deployment, the complexities of the setting may have ameliorated its impact on implementation.

Based on our experience of the intervention, we suggest that important factors to be considered when designing multi-methodology interventions to support group budgetary decisions in multi-organisational settings include exploring the relative implications of different budget allocations during the intervention design phase, and the way budget areas and options are structured in a portfolio model.

A few avenues for further research can be identified. First, a potentially interesting direction for future work is to conduct comparative evaluation studies of multimethodology interventions to support budgetary decisions. In particular, we would like to know which particular combinations of methodologies are more likely to lead to the full implementation of the intervention's recommendations. When qualitative 
and quantitative modelling approaches are used in a multi-methodology format, it would be interesting to examine the actual contribution of the different approaches to the overall impact of the intervention. Does organisational context determines whether a particular combination is deemed as effective? Under which circumstances does a transparent but contested (qualitative or quantitative) model become legitimate? Further research would shed some light into these questions.

Another research avenue worth pursuing relates to exploring the nature of benefits resulting from combining methods. Based on our observations during the intervention we argued that these benefits can have a linear and facilitative nature. That is, benefits obtained from using a particular method at the beginning of an intervention can help achieving the intended benefits of another method used later in the intervention. Unfortunately, we did not found evidence in the evaluation data for our claim and, therefore, this represents an area worthy of further investigation

Keys [70] posits that creativity and style play a major role in the design of management science interventions. Similarly, Cropper [71] argues that design of an intervention is influenced by the interventor's preferred approaches to decision support, as well as the interventor's preferred approaches in decision support. The latter consists of the theories-in-use held by interventors about the way decision support interventions can be planned and sensibly implemented. Our original multimethodology design reflected predominant concerns for certain effectiveness criteria: mapping was intended to stress divergent thinking and differentiation; multi-criteria decision analysis was intended to stress convergent thinking and integration. Other approaches in decision support are possible and more studies where these are made explicit by interventors would advance our understanding of multi-methodology practice.

Finally, the intervention reported shows that in the multi-organisational context within which the intervention was carried out, no particular criteria or values associated with decision making effectiveness were dominant. The values embedded within our approach to and in decision support as illustrated in the multi-methodology intervention also show no particular concern or criteria as dominant, i.e. we consider both divergence and convergence as necessary for effective group decision making. Yet the evidence presented here suggests that the lack of a dominant concern for rationality may have moderated the impact of the multi-criteria evaluation modelling stage. Recently Denis et al [72] provide empirical evidence that when the results of quantitative analysis map on to dominant values and concerns, it can overcome the voids created by pluralistic (e.g. multi-organisational) decision making contexts. Clearly this is an area which deserves further investigation.

We recognise the findings reported here are drawn from a single intervention which poses serious restrictions to their generasibility. We have, however, attempted to produce an account which is grounded in a systematic analysis of intervention data, combined with insights from our own experience of supporting decision making in other organisational settings. It is hoped that this paper may stimulate others to consider and evaluate alternative ways of deploying multi-methodology for research and praxis.

\section{References}


1. Mingers, J. and J. Brocklesby, Multimethodology: towards a framework for mixing methodologies. OMEGA, 1997. 25(5): p. 489-509.

2. Mingers, J. and A. Gill, eds. Multimethodology: the theory and practice of combining Management Science methodologies. 1997, Wiley: Chichester.

3. Jackson, M., Present Positions and Future Prospects in Management Science. OMEGA, 1987. 15(6): p. 455-466.

4. Pidd, M., Complementarity in systems modelling, in Systems Modelling: theory and practice, M. Pidd, Editor. 2004, Wiley: Chichester. p. 1-20.

5. Paucar-Caceres, A., Mapping the changes in management science: A review of 'soft' OR/MS articles published in Omega (1973-2008). OMEGA: The International Journal of Management Science, 2010. 38(1-2): p. 46-56.

6. Munro, I. and J. Mingers, The Use of Multimethodology in Practice: results from a survey of practitioners. Journal of Operational Research Society, 2002. 53(4): p. 369-378.

7. Mingers, J., Multimethodology: mixing and matching methods, in Rational Analysis for a Complex World Revisited: problem structuring methods for complexity, uncertainty and conflict, J. Rosenhead and J. Mingers, Editors. 2001, Wiley: Chichester. p. 289-310.

8. Eden, C., Cognitive Mapping: a review. European Journal of Operational Research, 1988. 36(1): p. 1-13.

9. Eden, C., Analyzing Cognitive Maps to Help Structure Issues or Problems. European Journal of Operational Research, 2004. 159(3): p. 673-686.

10. Bryson, J.M., et al., Visible Thinking: unlocking causal mapping for practical business results. 2004, Chichester: Wiley.

11. Belton, V. and T.J. Stewart, Multiple Criteria Decision Analysis: An integrated approach. 2002, Dordrecht: Kluwer.

12. Bana e Costa, C.A., et al., Facilitating Bid Evaluation in Public Calls for Tenders: a socio-technical approach. OMEGA, 2002. 30(3): p. 227-242.

13. Belton, V., F. Ackermann, and I. Shepherd, Integrated Support from Problem Structuring through to Alternative Evaluation Using COPE and VISA. Journal of Multi-Criteria Decision Analysis, 1997. 6(3): p. 115-130.

14. Bana e Costa, C.A., et al., Decision Support Systems in Action: integrated application in a multi-criteria aid process. European Journal of Operational Research, 1999. 113(2): p. 315-335.

15. Barcus, A. and G. Montibeller, Supporting the Allocation of Software Development Work in Distributed Teams with Multi-criteria Decision Analysis. OMEGA, 2008. 36(3): p. 464-475.

16. SEU, Bridging the Gap: new opportunities for 16-18 year olds not in employment, education or training. 1999, The Stationary Office: London.

17. Eden, C. and C. Huxham, Action Research for the Study of Organizations, in Studying Organization: theory and method, S. Clegg and C. Hardy, Editors. 1999, Sage: London. p. 272-288.

18. Checkland, P. and S. Holwell, Action Research: its nature and validity. Systemic Practice and Action Research, 1998. 11(1): p. 9-21.

19. Kaner, S., Facilitator's Guide to Participatory Decision Making. 2007, San Francisco, CA: Jossey-Bass.

20. Russo, J.E. and P.J.H. Schoemaker, Decision Traps: the ten barriers to brilliant decision-making and how to overcome them. 1989, New York: Simon and Schuster. 
21. Jackson, M. and P. Keys, Towards a System of Systems Methodologies. Journal of the Operational Research Society,, 1984. 35(6): p. 473-486.

22. Flood, R.L. and M. Jackson, Creative Problem Solving: Total Systems Intervention. 1991, Chichester: Wiley.

23. Midgley, G., Mixing methods: Developing systemic intervention, in Multimethodology: The theory and practice of combining Management Science methodologies, J. Mingers and A. Gill, Editors. 1997, Wiley: Chichester. p. 249-290.

24. Cropper, S., Variety, Formality, and Style: Choosing Amongst DecisionSupport Methods, in Tackling Strategic Problems: the role of group decision support, C. Eden and J. Radford, Editors. 1990, Sage: London. p. 92-98.

25. Bennett, P.G., On Linking Approaches to Decision-Aiding: issues and prospects. Journal of Operational Research Society, 1985. 36(8): p. 659-669.

26. White, L. and A. Tacket, Critiquing multimethodology as metamethodology: Working towards pragmatic pluralism, in Multimethodology: The theory and practice of combining Management Science methodologies., J. Mingers and A. Gill, Editors. 1997, Wiley: Chichester. p. 379-405.

27. Ormerod, R., The Transformation Competence Perspective. Journal of the Operational Research Society, 2008. 59(11): p. 1435-1448.

28. Bennett, P.G., et al., Analysing Litigation and Negotiation: Using a combined methodology, in Multimethodology: The theory and practice of combining methodologies., J. Mingers and A. Gill, Editors. 1997, Wiley: Chichester. p. 59-88.

29. Mingers, J., A Classification of the Philosophical Assumptions of Management Science Methods. Journal of the Operational Research Society, 2003. 54: p. 559-570.

30. Mingers, J., Variety is the Spice of Life: combining soft and hard OR/MS methods. International Transactions in Operational Research, 2000. 7(6): p. 673-691.

31. Franco, L.A. and G. Montibeller, Facilitated Modelling in Operational Research (Invited Review). European Journal of Operational Research, 2010. 205(3): p. 489-500.

32. Phillips, L., A Theory of Requisite Decision Models. Acta Psychologica, 1984. 56(1-3): p. 29-48.

33. Brocklesby, J., Becoming multimethodology literature: An assessment of the cognitive difficulties of working across paradigms, in Multimethodology: The theory and practice of combining management science methodologies. 1997, Chichester: Wiley. p. 189-216.

34. Pidd, M., Bringing it all together, in Systems Modelling:theory and practice, M. Pidd, Editor. 2004, John Wiley and Sons: Chichester. p. 197-207.

35. Kotiadis, K. and J. Mingers, Combining PSMs with hard OR methods: the philosophical and practical challenges. Journal of the Operational Research Society, 2006. 57(7): p. 856-867.

36. Jackson, M., Systems Approaches to Management. 2000, New York: Kluwer.

37. Jackson, M.C., Beyond problem structuring methods: reinventing the future of OR/MS. Journal of the Operational Research Society, 2006. 57(7): p. 868-878.

38. Jackson, M.C., Systems Thinking: Creative Holism for Managers. 2003, Chichester: Wiley.

39. Keys, P., On Becoming Expert in the Use of Problem Structuring Methods. Journal of the Operational Research Society, 2006. 57(7): p. 822-829. 
40. Pollack, J., Multimethodology in series and parallel: strategic planning using hard and soft OR. Journal of the Operational Research Society, 2009. 60: p. 156-167.

41. Phillips, L. and C.A. Bana e Costa, Transparent Prioritisation, Budgeting, and Resource Allocation with Multi-Criteria Decision Analysis and Decision Conferencing. Annals of Operations Research, 2007. 154(1): p. 51-68.

42. Keeney, R.L., Value-Focused Thinking: a path to creative decision-making 1992, Cambridge, MA: Harvard University Press.

43. Keeney, R.L., Developing Objectives and Attributes, in Advances in Decision Analysis, W. Edwards, R.F. Miles, and D. von Winterfeldt, Editors. 2007, Cambridge Unniversity Press: Cambridge. p. 104-128.

44. Poyhonen, M., H. Vrolijk, and R.P. Hamalainen, Behavioral and procedural consequences of structural variation in value trees. European Journal of Operational Research, 2001. 134: p. 216-227.

45. Weber, M., F. Eisenführ, and D. von Winterfeldt, The Effects of Splitting Attributes on Weights in Multi-Attribute Utility Measurement. Management Science, 1988. 34(4): p. 431-445.

46. Montibeller, G. and V. Belton, Causal Maps and the Evaluation of Decision Options: a review. Journal of the Operational Research Society, 2006. 57(7): p. 779-791.

47. De Geus, A., Planning as Learning. Harvard Business Review, 1988. 66(2): p. 70-74.

48. Eden, C., A Framework for Thinking About Group Decision Support Systems. Group Decision and Negotiation, 1992. 1: p. 199-218.

49. Strauss, A. and J. Corbin, Basics of Qualitative Research: techniques and procedures for developing grounded theory. 1998, London: Sage.

50. White, L., Evaluating Problem Structuring Methods: developing an approach to show the value and effectiveness of PSM interventions. Journal of the Operational Research Society, 2006. 57(7): p. 842-855.

51. Franco, L.A., Facilitating Collaboration with Problem Structuring Methods: a case of an inter-organisational construction partnership. Group Decision and Negotiation, 2008. 17(4): p. 267-286.

52. Shaw, D., Evaluating Electronic Workshops Through Analysing the 'Brainstormed' Ideas. Journal of the Operational Research Society, 2003. 54(7): p. 692-705.

53. Turner, B., The Use of Grounded Theory for the Qualitative Analysis of Organizational Behaviour. Journal of Management Studies, 1983. 20(3): p. 333-348.

54. Eden, C., F. Ackermann, and S. Cropper, The Analysis of Cause Maps. The Journal of Management Studies, 1992. 29(3): p. 309-324.

55. Rouwette, E.A.J.A., J.A.M. Vennix, and A.J.A. Felling, On Evaluating the Performance of Problem Structuring Methods: An attempt at formulating a conceptual model. Group Decision and Negotiation, 2009. 18: p. 567-587.

56. Franco, L.A., Forms of Conversation and Problem Structuring Methods: a conceptual development. Journal of the Operational Research Society, 2006. 57(7): p. 813-821.

57. White, L. and H. Bourne, Voices and values: Linking values with participation in OR/MS in public policy making. OMEGA: The International Journal of Management Science, 2006. 35(5): p. 588-603. 
58. Franco, L.A., Problem Structuring Methods as Intervention Tools: reflections from their use with multi-organizational teams. OMEGA, 2009. 37(1): p. 193203.

59. Keeney, R.L. and H. Raiffa, Decisions with Multiple Objectives: preferences and value trade-offs. 2nd ed. 1993, Cambridge, MA: Cambridge University Press.

60. Checkland, P. and J. Scholes, Soft Systems Methodology in Action. 1990, Chichester: Wiley.

61. Ulrich, W., Critical Heuristics of Social Planning. 1994, Chiohester: John Wiley \& Sons.

62. Franco, L.A., Assessing the Impact of Problem Structuring Methods in Multiorganisational Settings: an empirical investigation. Journal of the Operational Research Society, 2007. 58(6): p. 760-768.

63. Rouwette, E.A.J.A., J.A.M. Vennix, and T. van Mullekom, Group Model Building Effectiveness: a review of assessment studies. System Dynamics Review, 2002. 18(1): p. 5-45.

64. Goodwin, P. and G. Wright, Decision Analysis for Management Judgment. 3rd ed. 2004, Chichester: Wiley.

65. Eden, C. and F. Ackermann, Strategy Making: the journey of strategic management. 1998, London: Sage.

66. Rosenhead, J. and J. Mingers, eds. Rational Analysis for a Problematic World Revisited: problem structuring methods for complexity, uncertainty and conflict. 2001, Wiley: Chichester.

67. Langley, A., In Search of Rationality: the purposes behind the use of formal analysis in organizations. Administrative Science Quarterly, 1989. 34(4): p. 598-631.

68. Langley, A., Formal Analysis and Strategic Decision Making. OMEGA: The International Journal of Management Science, 1991. 2(3): p. 79-99.

69. Brunsson, N., The Irrationality of Action and Action Rationality: decisions, ideologies and organizational actions. Journal of Management Studies, 1982. 19(1): p. 29-44.

70. Keys, P., Creativity, design and style in MS/OR. OMEGA: The International Journal of Management Science, 2000. 28(3): p. 303-312.

71. Cropper, S., The Complexity of Decision Support Practice, in Tackling Strategic Probems: the role of group decision support, C. Eden and J. Radford, Editors. 1990, Sage: London. p. 29-39.

72. Denis, J.-L., A. Langley, and L. Rouleau, The Power of Numbers in Strategizing. Strategic Organization, 2006. 4(4): p. 349-377. 
Figure 1: Excerpt from a cognitive mapping interview

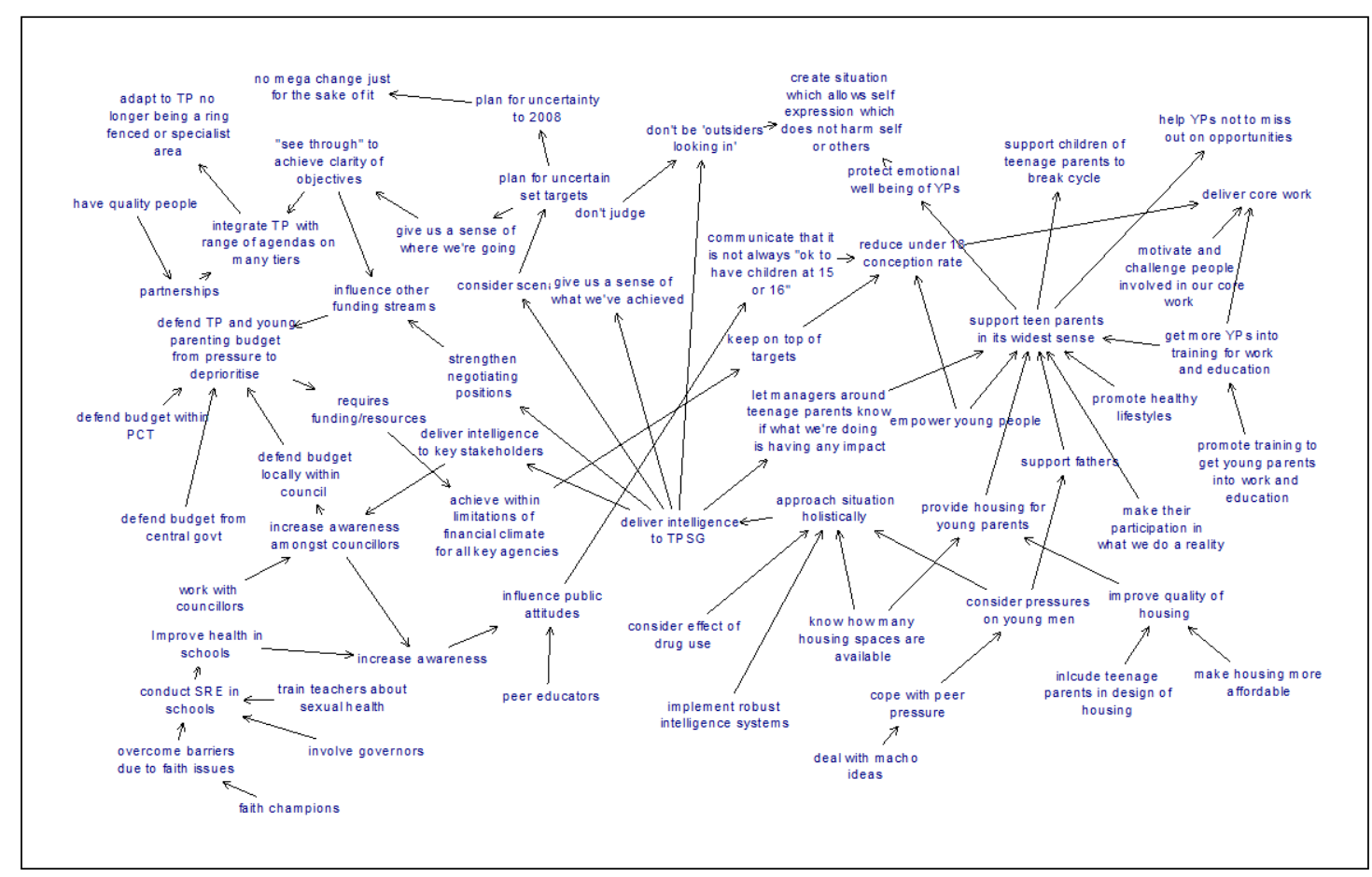


Franco, L.A. \& Lord, E. Understanding Multi-Methodology (to appear in OMEGA)

Figure 2: Overview of initial TPSC project prioritisation model

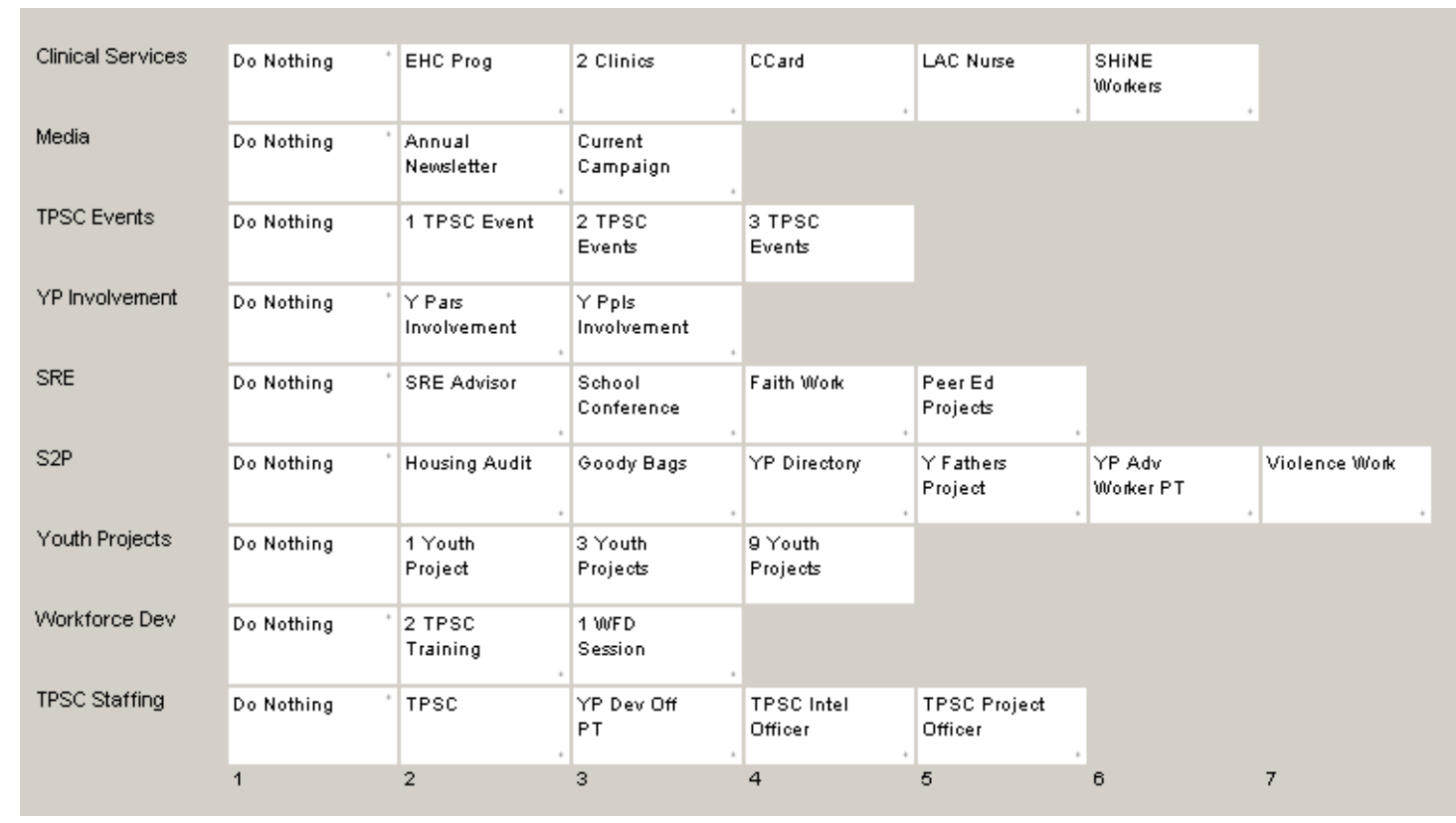


Figure 3: The ‘envelope’ of all possible portfolios for TPSC using the Equity software.

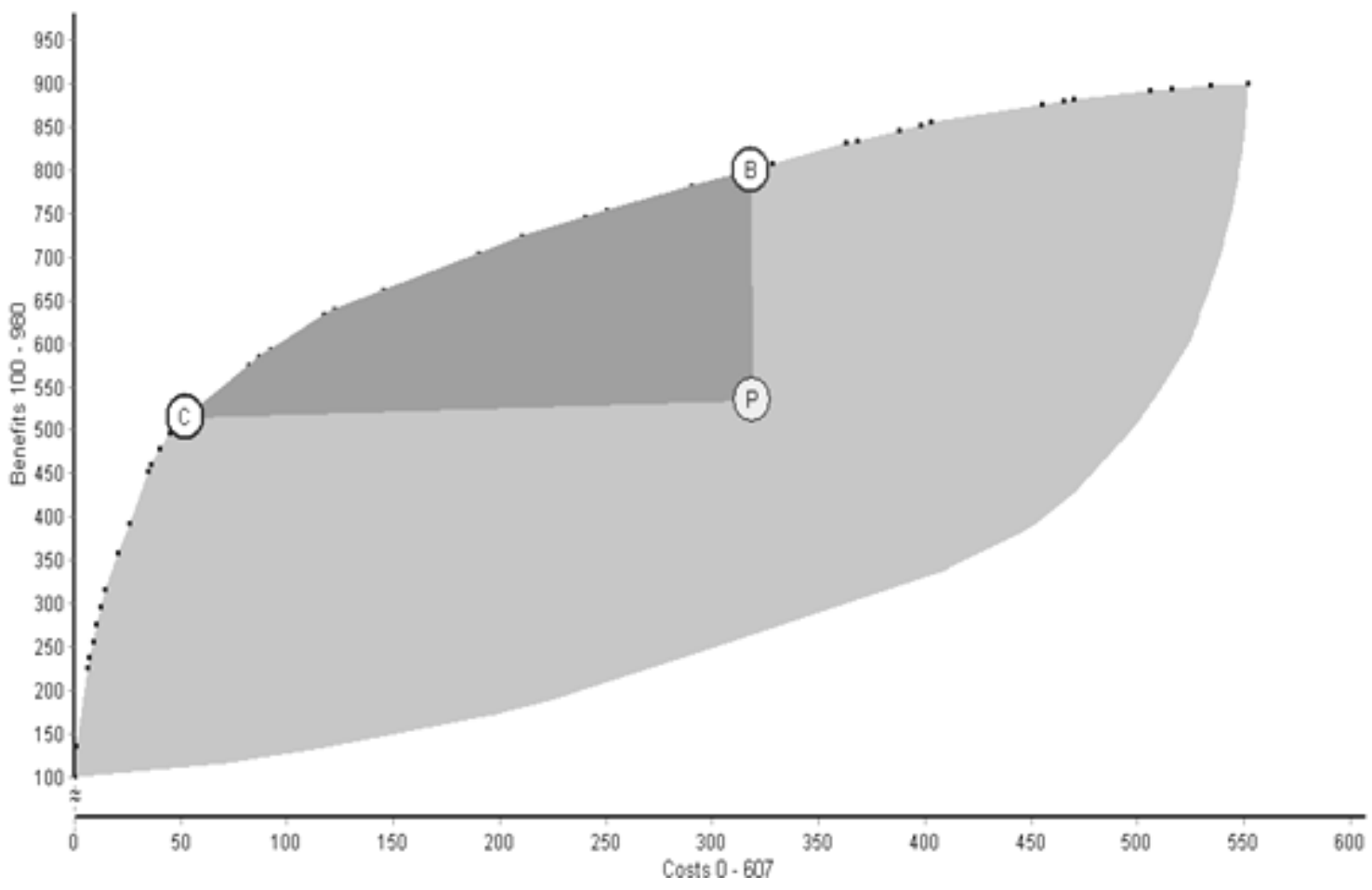

